\title{
Modeling of Intellite 3 Layer Deformable Mirror
}

\author{
Alexandros P. Papavasiliou
}

\section{April 15, 2002}

U.S. Department of Energy

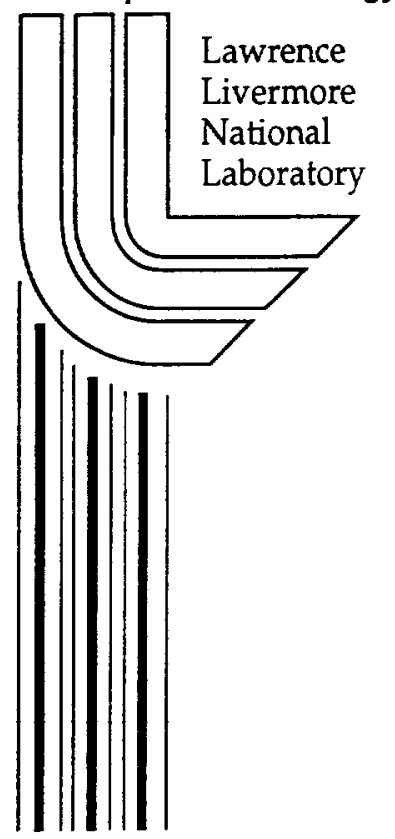




\section{DISCLAIMER}

This document was prepared as an account of work sponsored by an agency of the United States Government. Neither the United States Government nor the University of California nor any of E.eir employees, makes any warranty, express or implied, or assumes any legal liability or responsibility :or the accuracy, completeness, or usefulness of any information, apparatus, product, or process disclose $\dot{\epsilon}$. or represents that its use would not infringe privately owned rights. Reference herein to any specific commercial product, process, or service by trade name, trademark, manufacturer, or otherwise, does not necessarily constitute or imply its endorsement, recommendation, or favoring by the United Stzies Government or the University of California. The views and opinions of authors expressed herein do not necessarily state or reflect those of the United States Government or the University of California, and shall not be used for advertising or product endorsement purposes.

This work was performed under the auspices of the U. S. Department of Energy by the Universit: of California, Lawrence Livermore National Laboratory under Contract No. W-7405-Eng-48.

This report has been reproduced directly from the best available copy.

Available to DOE and DOE contractors from the Office of Scientific and Technical Information

P.O. Box 62, Oak Ridge, TN 37831

Prices available from (423) 576-8401

http://apollo.osti.gov/bridge/

Available to the public from the National Technical Information Service

U.S. Department of Commerce 5285 Port Royal Rd., Springfield, VA 22161

http://www.ntis.gov/

OR

Lawrence Livermore National Laboratory Technical Information Department's Digital Library

http://www.llnl.gov/tid/Library.html 


\section{Modeling of Intellite 3 Layer Deformable Mirror}

This is a report on modeling of the Intellite three layer membrane mirror design. The goal of this project was to provide Intellite with a model that will allow them to design a mirror with confidence.

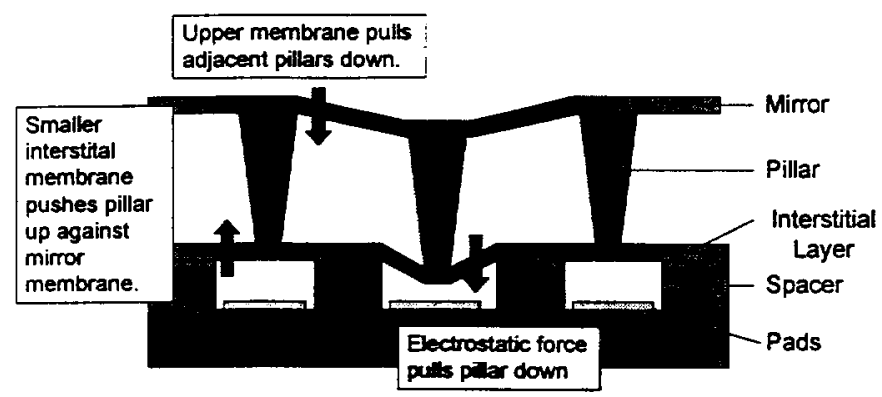

Figure 1 Cross Section of Intellite 3 Layer Mirror

\section{FEM Verification}

The first task was to determine how to use the FEM software to solve systems like to the membrane mirror. A simple system that behaves similarly to the Intellite design was modeled by COSMOS FEM and by Intellite FEM, and compared to an accepted model. The system used was a thin circular plate, clamped at the edges with a point force applied at the center. This disk is similar to the area surrounding one actuator in an Intellite membrane mirror with hexagonal actuator spacing.

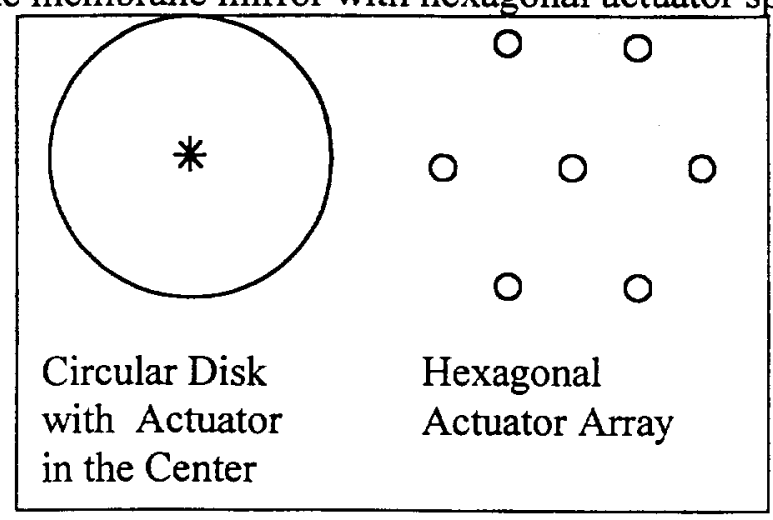

Figure 2 Circular Plate, and Hexagonal Actuator

Theory of Plates and Shells by Timoshenko [1] includes an "Approximate" formula for the deflection of a thin circular plate with clamped 
edges. $F=\frac{1}{B} \frac{E h^{3}}{R^{2}} x+\frac{A}{B} \frac{E h}{R^{2}} x^{3}$, where $\frac{1}{B}=4.608$ and $\frac{A}{B}=2.041$ for Poisson's ratio $\mathrm{v}=0.3$.

The COSMOS FEM model used was a quarter disk with a radius of $1 \mathrm{~mm}$. The straight edges of the quarter disk were fixed to move only in the radial direction and fixed to only have rotation perpendicular to the radial direction thus simulating a full disk while using only a quarter of the processing power. The disk was automatically meshed with a 50 micron grid with a 1 micron grid size concentration at the center of the disk. Models of this size could be finished in less than 10 minutes on a desktop PC. The convergence accuracy of the Intellite software is highly dependant on the grid size. The results reported here were attained using 500 elements, requiring several hours to converge to a solution.

The results of the comparison between COSMOS FEM, Intellite FEM and Timoshenko's theory, are shown in Figure 3. The non-linear FEM shows good correlation with the formula given in Timoshenko, it only starts to diverge at high deflections. By 10 microns of deflection the force is off by $38 \%$. However, the COSMOS results are so consistent that one might question the accuracy of Timoshenko's "approximate" method at this deflection. The results from the Intellite software were less encouraging. The required computation time limited the number of data points taken, but the points taken are rather erratic showing neither a smooth curve nor very accurate correspondence to the Timoshenko solution.

The results of the analysis create quite a bit of doubt if the goals of the NRO project can be achieved. The original goal of the NRO project was to deflect a mirror 30 microns electrostaticly. The plot shows that 30 microns of deflection will require on the order of $10,000 \mu \mathrm{N}$ instead of the perhaps $30 \mu \mathrm{N}$ that would be required by a membrane if it had a purely linear response. The actuation force for this device will come from a parallel plate electrostatic actuator. At 300 volts, with a square millimeter of area and a gap of 90 microns, what would be required to prevent snap-down, an electrostatic actuator produces around $50 \mu \mathrm{N}$. If the mirror does indeed behave similarly to this thin disk, the maximum actuator to actuator deflection will be on the order of 5 microns. 


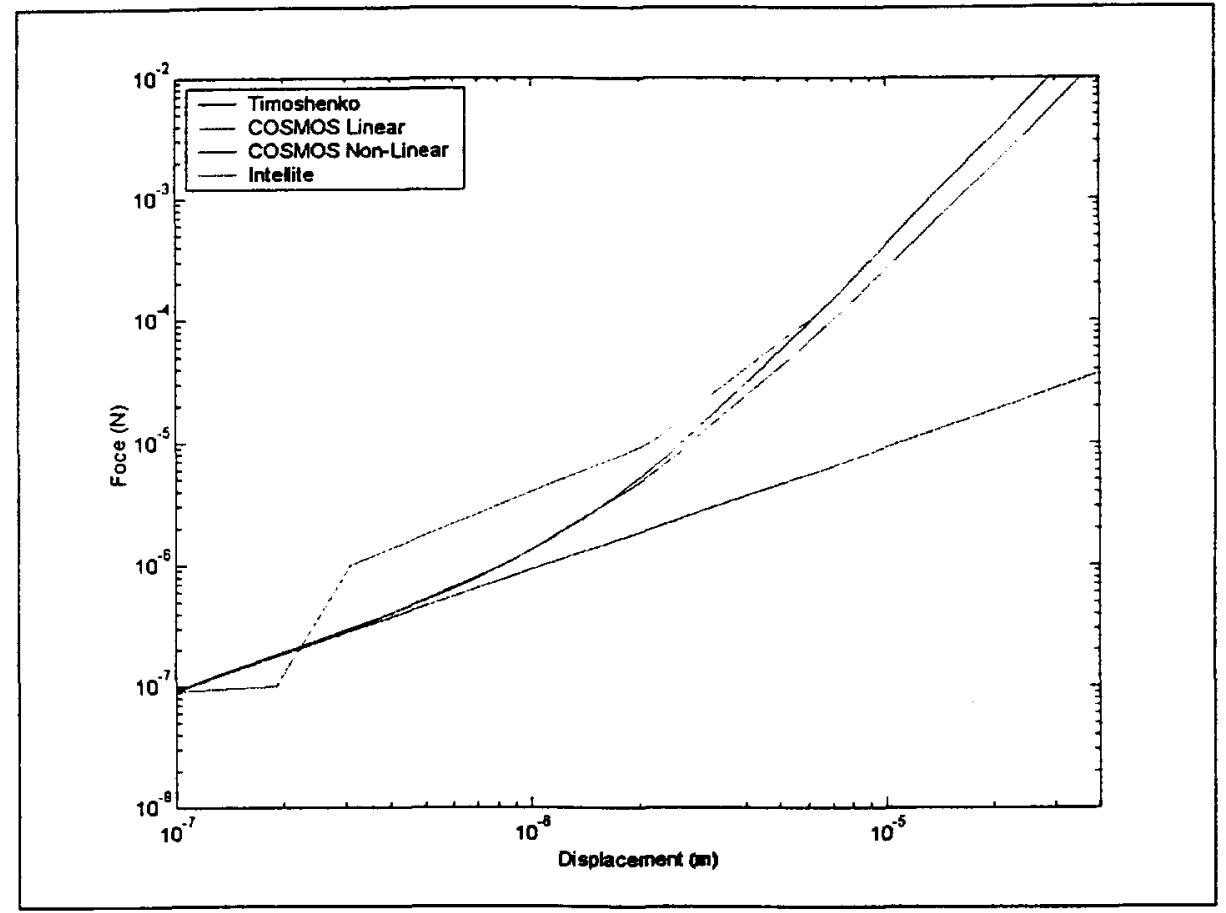

Figure 3 Comparison of Plate Models

If silicon is too stiff to make a mirror which can deform 30 microns between actuators there are two possibilities: 1) find a more appropriate material, or 2) scale back the requirements and continue to find more accurate models and different designs to determine the limitations of a silicon mirror.

\section{Alternate Materials}

First a brief study was carried out on the alternatives to silicon. Timoshenko's nostress approximate model was used as the basis for the study. The applied force was assumed to be $50 \mu \mathrm{N}$, approximately what an electrostatic actuator would be able to produce and disk radius was held at $1 \mathrm{~mm}$. Displacement was then plotted as a function of membrane thickness for a variety of Young's moduli. The results are shown in Figure 4.The plot suggests that the optimal young's modulus is around 1GPa. Mylar at a Young's modulus of around $7 \mathrm{GPa}$, is a little bit too stiff, and Silicone elastomers at around $5 \mathrm{MPa}$ are several orders of magnitude weaker than is required. 


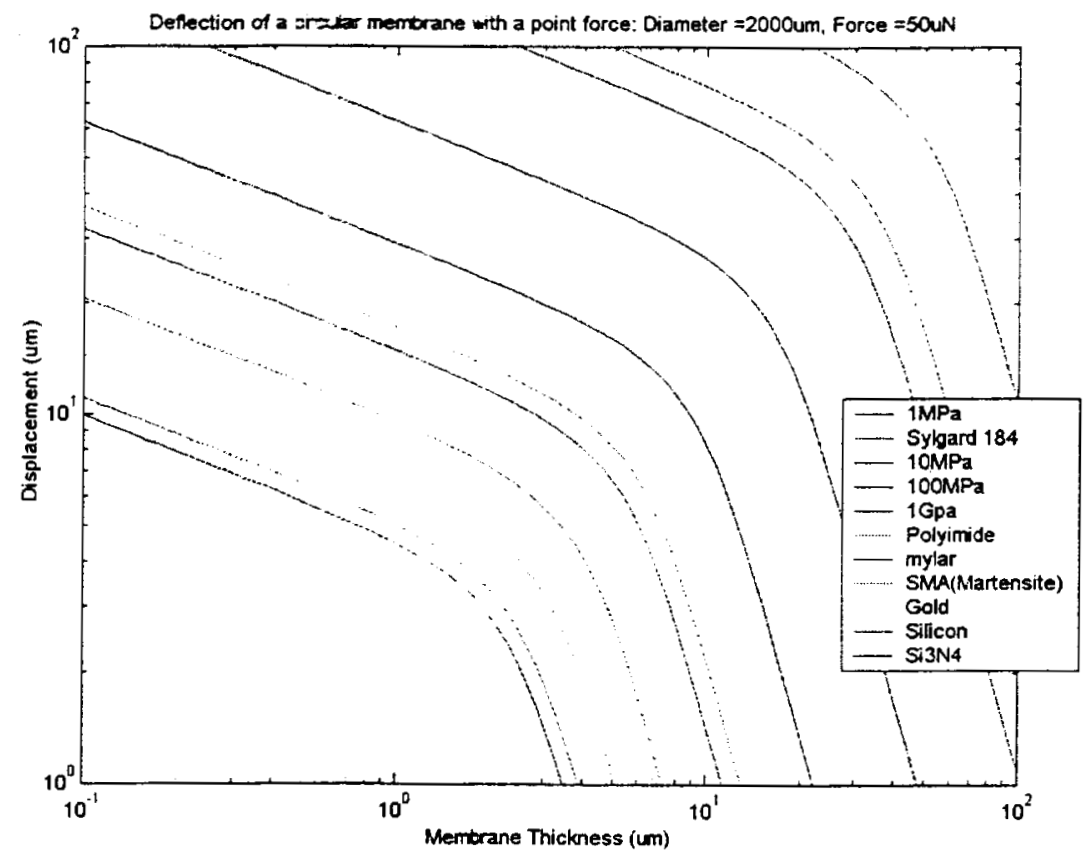

Figure 4 Comparison of Materials for Memebrane Mirrors

\section{Residual Stress}

Study of silicon was continued to determine exactly how far a silicon membrane mirror could be expected to deflect. The first level of realism added was residual stress. Since it is very difficult to control the residual stress of a silicon membrane exactly and a residual compressive stress might lead to undesired buckling or wrinkling, any real membrane mirror would undoubtedly be fabricated with a residual tensile stress. The next study was done on the effect of residual stress on the plate.

The same plate (radius $=1 \mathrm{~mm}$, thickness $=1 \mu \mathrm{m}, \mathrm{E}=200 \mathrm{GPa}$, Poisson's ratio $=0.3$ ) was modeled with a temperature boundary condition that imposes a residual strain, and thus a residual stress. The force vs. Displacement curve was generated for stresses of $0 \mathrm{MPa}, 1 \mathrm{MPa}, 10 \mathrm{MPa}, 20 \mathrm{MPa}$, and $1 \mathrm{MPa}$ compressive. The results are plotted in Figure 5. 


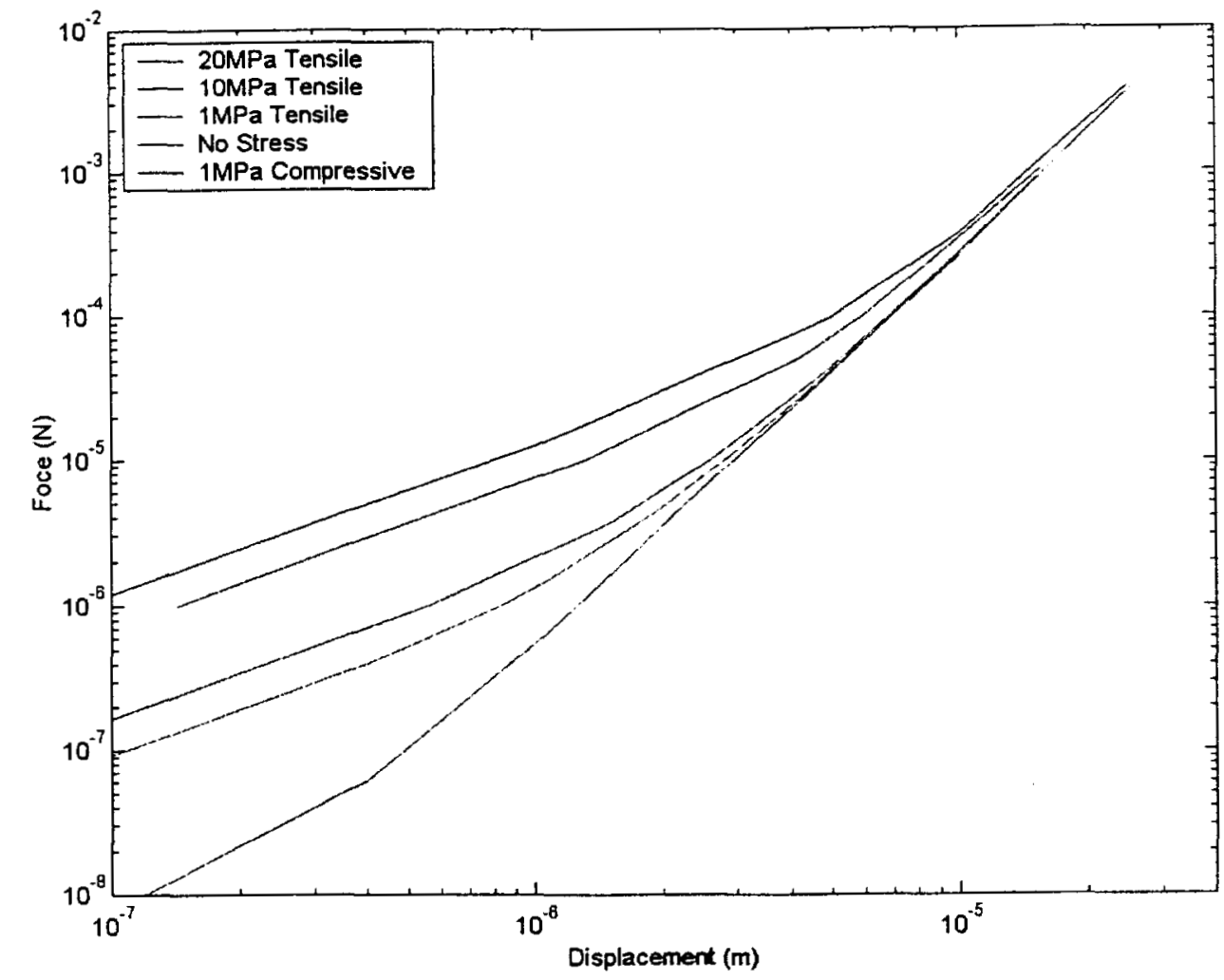

Figure 5 Circular Plate With Various Initial Stress Conditions

The curves generated by these experiments coincide into one line at large deformations, but diverge with higher stress plates being stiffer at low deflections. In form this is very similar to the behavior of another non-linear system, the fixed-guided beam. Much like a plate with fixed edges, the fixed-guided beam is dominated by a linear, bending term at small deflections, and dominated by a non-linear stretching term at large defections. Both can be approximated by a cubic equation similar to the one presented by Timoshenko.

$$
\begin{aligned}
& F=\frac{1}{B} \frac{E h^{3}}{R^{2}} x+\frac{A}{B} \frac{E h}{R^{2}} x^{3} \text { (Timoshenko, circular plate) } \\
& F=\frac{E b h^{3}}{L^{3}} x+C_{2} \frac{E b h}{L^{3}} x^{3} \quad \text { (Clamped-Guided beam) [2] }
\end{aligned}
$$

The Fixed guided beam also behaves similarly to the plate when residual stress is considered. A residual tensile stress has the effect of stiffening the linear bending term while not changing the non-linear stretching term. The deformation of a fixed-guided beam with tensile stress can be approximated as: $F=\left(\frac{E w h^{3}}{L^{3}}+C_{1} \frac{b w}{L} \sigma_{r}\right) x+C_{2} \frac{E b w}{L^{3}} x^{3}$ where $\mathrm{C} 1$ and $\mathrm{C} 2$ are constants that can be determined through extensive analytical or FEM modeling. 
The parameters from Timoshenko's form were used except the young's modulus, E, which was replaced with the biaxial modulus, $M=\frac{E}{(1-v)}$, to make the coefficients independent of Poisson's ratio. The resulting form is:

$F=\left(C_{1} \frac{M t^{3}}{R^{2}}+C_{2} t \sigma_{r}\right) x+C_{3} \frac{M t}{R^{2}} x^{3}$. The coefficients were determined by fitting to FEM results using a least squares method. Since the range to be fit varied over several orders of magnitude, percentage error squared was minimized instead of absolute error. The results of the fit are, $\mathrm{Cl}=3.9060, \mathrm{C} 2=0.5493$, and $\mathrm{C} 3=0.8939$. The fit plotted against the FEM results shown above is shown in Figure 6. Except for the data for compressive stress, the fit to data is very good. The average error for the $78 \mathrm{FEM}$ data points over a range of tensile stresses (excluding compressive stresses) and plate thicknesses was $0.4548 \%$.

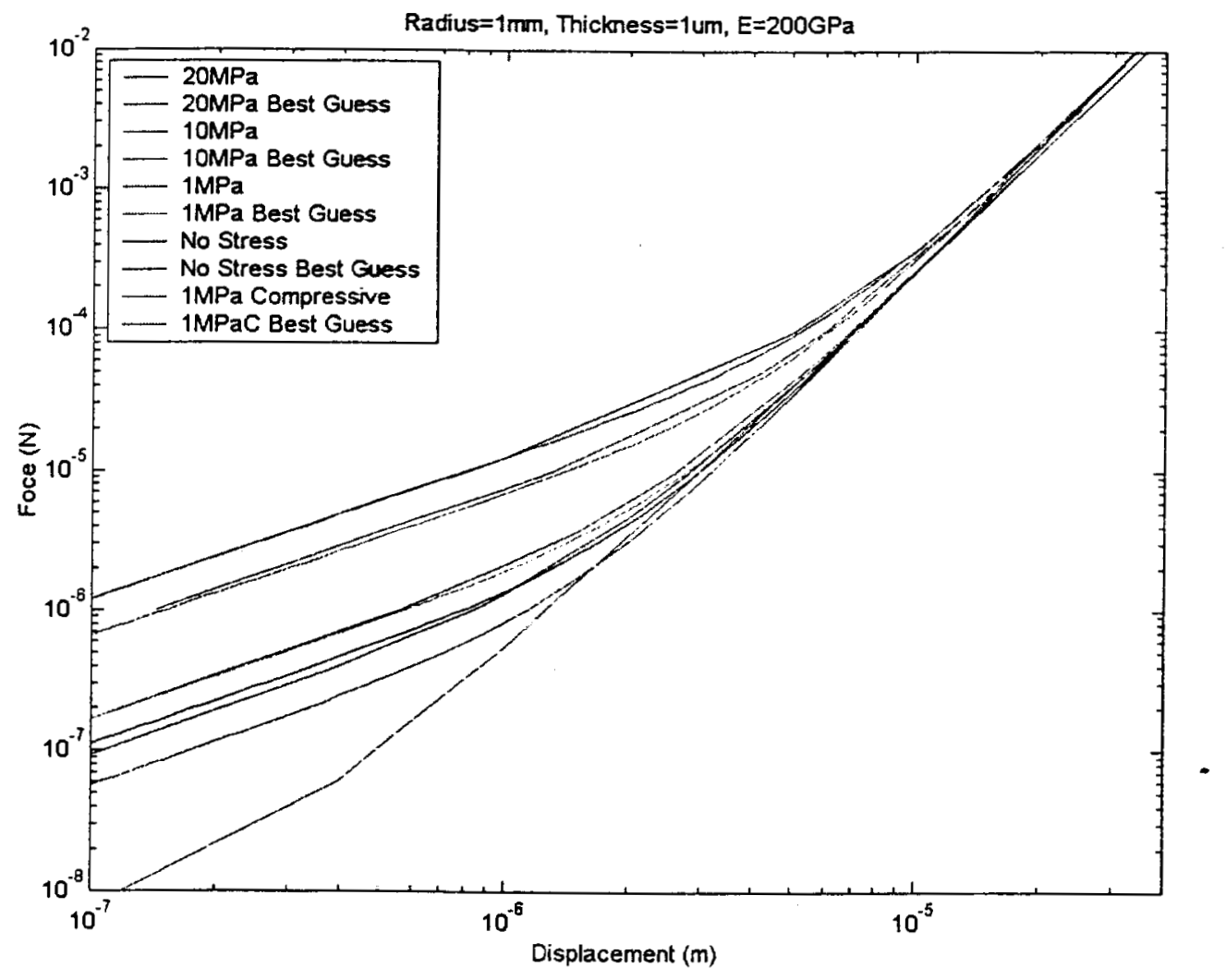

Figure 6 Fit to FEM Data

\section{Spring and Plate Model}

The next step was to try to model a mirror with springs attached to the ends to simulate the interstitial layer. The model used attempts to simulate the area around the actuator, the nearest neighbor, and the second nearest neighbor. Using symmetry, this was simulated with a wedge that covers $1 / 12^{\text {th }}$ of that area as shown in Figure 7. The top corner is the point where the actuator is attached. There is also a spring with $1 / 12^{\text {th }}$ of the stiffness of the interstitial spring attached at that point. Half way down the left side is a 
spring that simulates the nearest neighbor spring, by symmetry about the vertical and horizontal edges of the wedge, this spring simulates all of the nearest neighbors. Along the base of the wedge are two springs representing the second nearest neighbors.

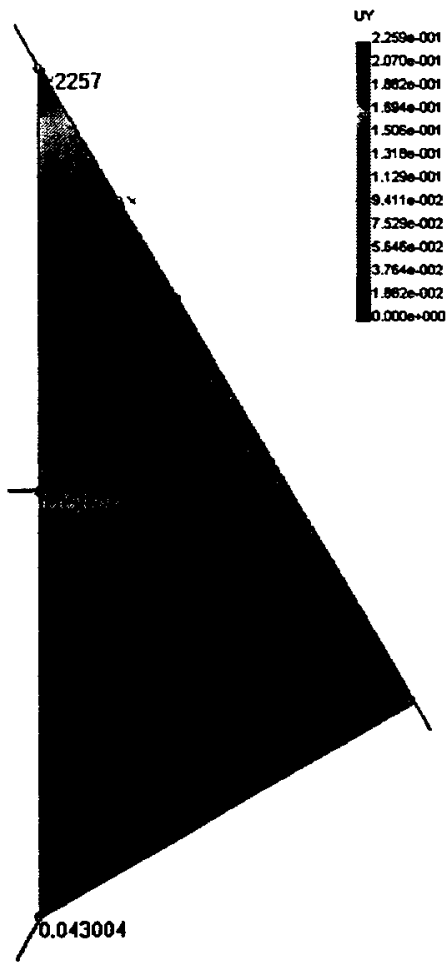

Figure 7 Top View of FEM Model

The behavior of the model is measured by applying a force at the apex of the wedge and measuring the displacement at the actuator, the nearest neighbor, and the second nearest neighbor. A side view of the actuation is shown in Figure 8.

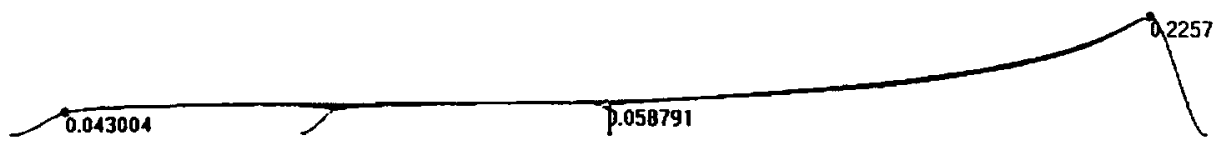

Figure 8 Side Veiw of Deformed FEM Model

Displacement of the actuator, nearest neighbor, and second nearest neighbor were measured for an actuator force of $1,5,10$, and $50 \mathrm{uN}$, with interstitial spring constants of $0.1,0.25,0.5,1,2$, and $5 \mathrm{~N} / \mathrm{m}$. The raw results are shown in Figure 9. Here force is in $\mathrm{uN}$, D0 indicates displacement of the primary actuator, D1 indicates displacement of the nearest neighbor, and D2 indicates the displacement of the second nearest neighbor. 


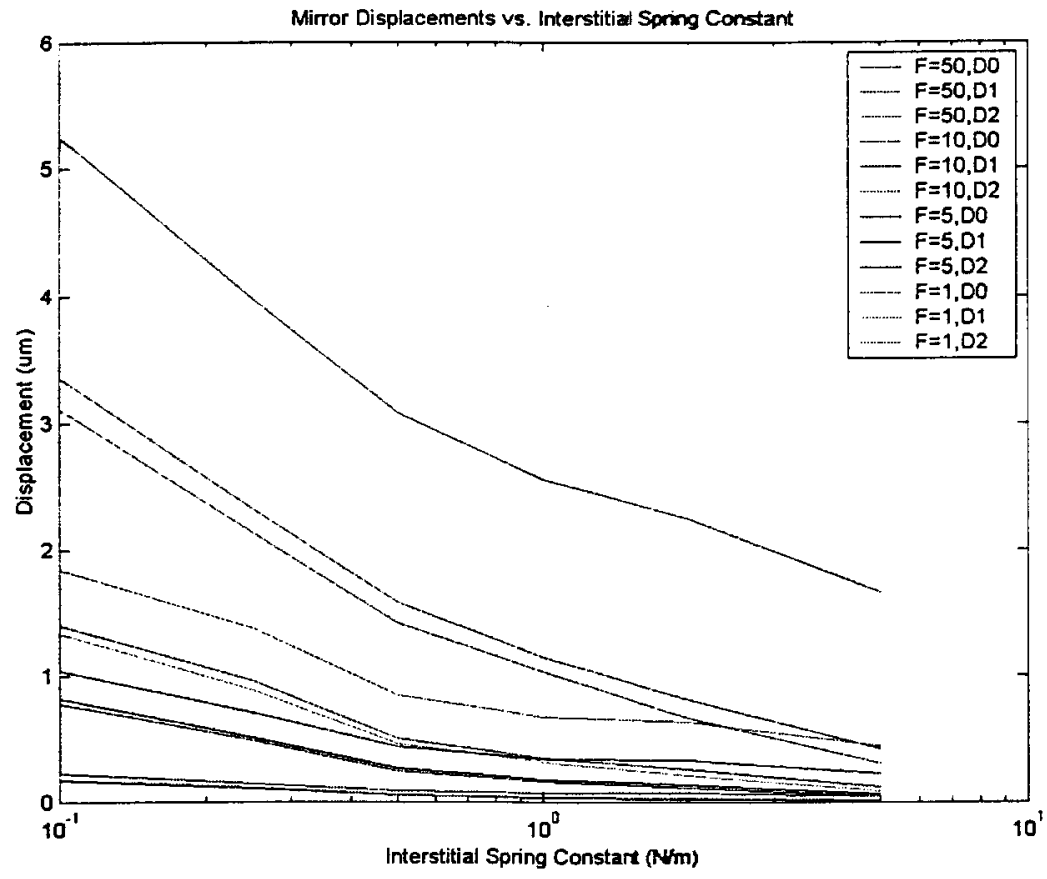

Figure 9 Raw Displacement Data

The raw displacement information looks fairly promising. It appears that with a very weak spring constant, one observes more than 5 microns of displacement. However, what is really important is not the absolute displacement, but the difference between the displacement of the actuator and the displacement of its neighbors. The displacement of the primary actuator minus the displacement of the nearest neighbor is plotted in Figure 10. 


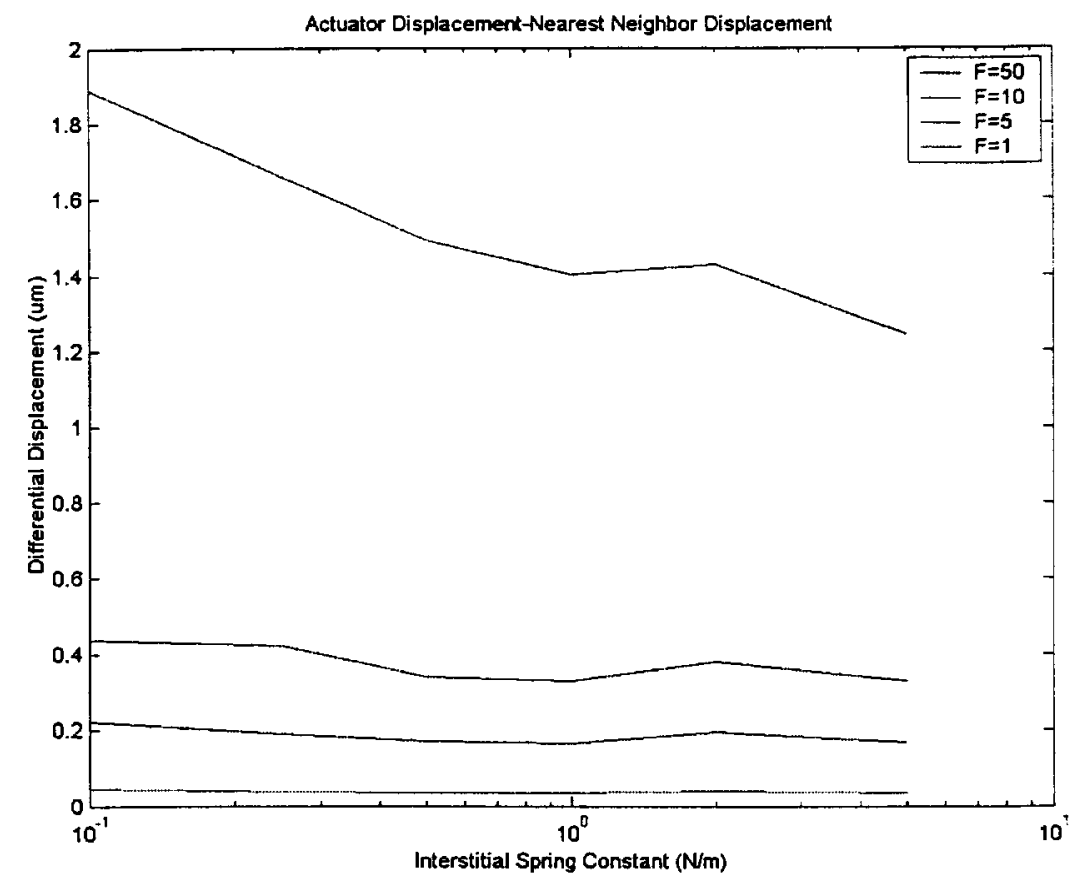

Figure 10 Differential Displacement Data

This shows a decrease in displacement as spring constant increases as one would expect. It also shows a maximum displacement, with a very weak spring, of less than 2 microns. Another important parameter is how much the nearest neighbor is affected by the displacement of the actuator. To show this, the nearest neighbor deflection was divided by the actuator deflection. However, this is not really accurate. In the model, the entire wedge can move by stretching the interstitial springs but, in a real mirror, with thousands of actuators and mirrors, no one actuator would be able to displace all of the actuators and springs. To correct for the bulk movement of the model, the second nearest neighbor deflection was subtracted from the actuator deflection and the nearest neighbor deflection before they were compared. The results of this are shown in Figure 11 


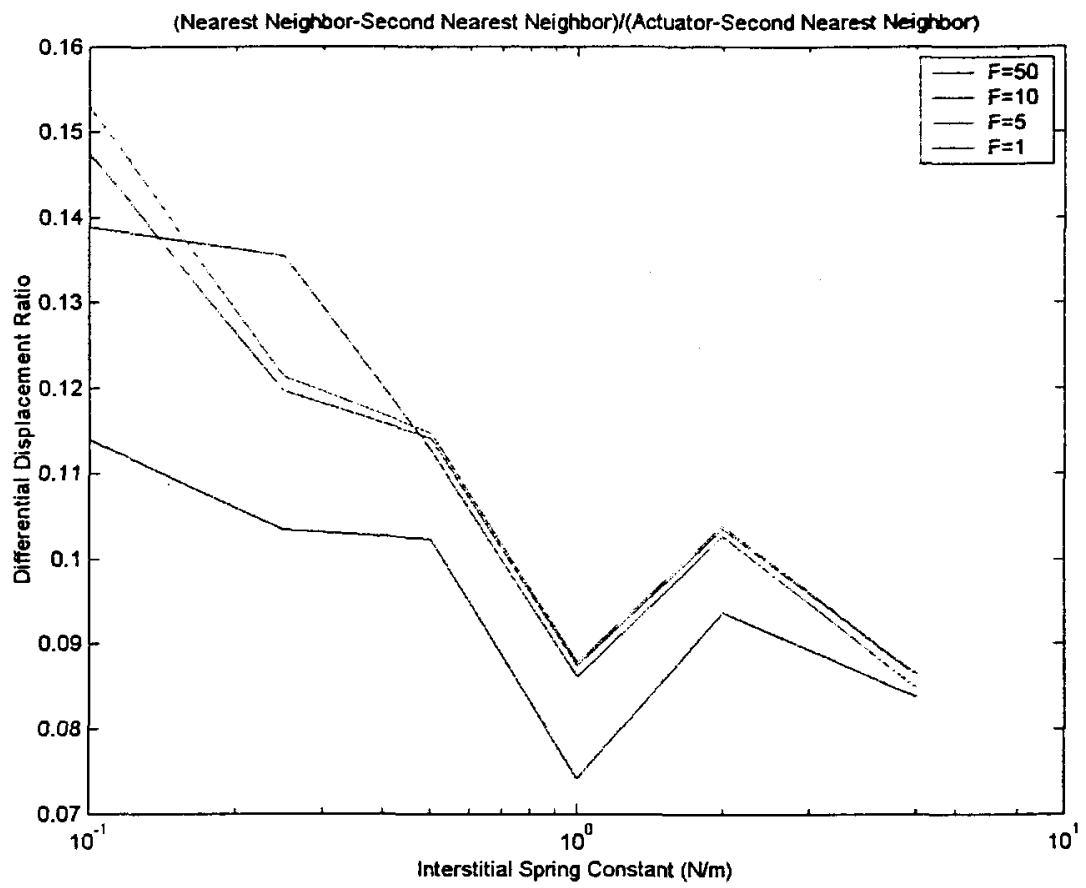

Figure 11 Influence of Actuator on Nearest Neighbor

Some work was done on trying to integrate analytical models with the FEM results that were done with integrated springs. However, without an analytical model of the behavior of the mirror surface beyond the first nearest neighbor actuators, it is difficult to draw direct parallels. The system was modeled as a system of springs including the actuator interstitial spring, $\mathrm{Ki}$, the nearest neighbor interstitial springs and the mirror surface as a non linear spring, $\mathrm{Km}$ as shown in Figure 12.

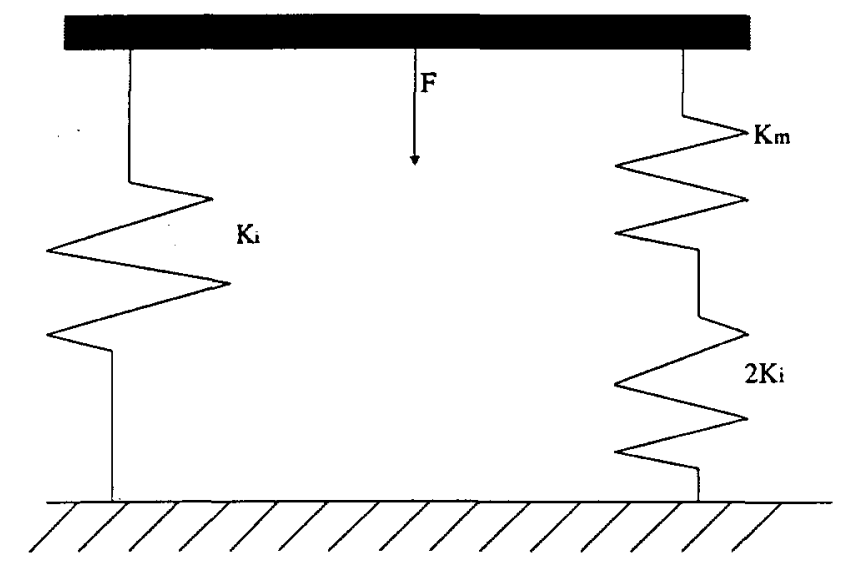

Figure 12 Spring System Model

The results for differential displacement of the actuator and the nearest neighbor, shown in Figure 13, differ from the FEM model by more than a factor of 2. 


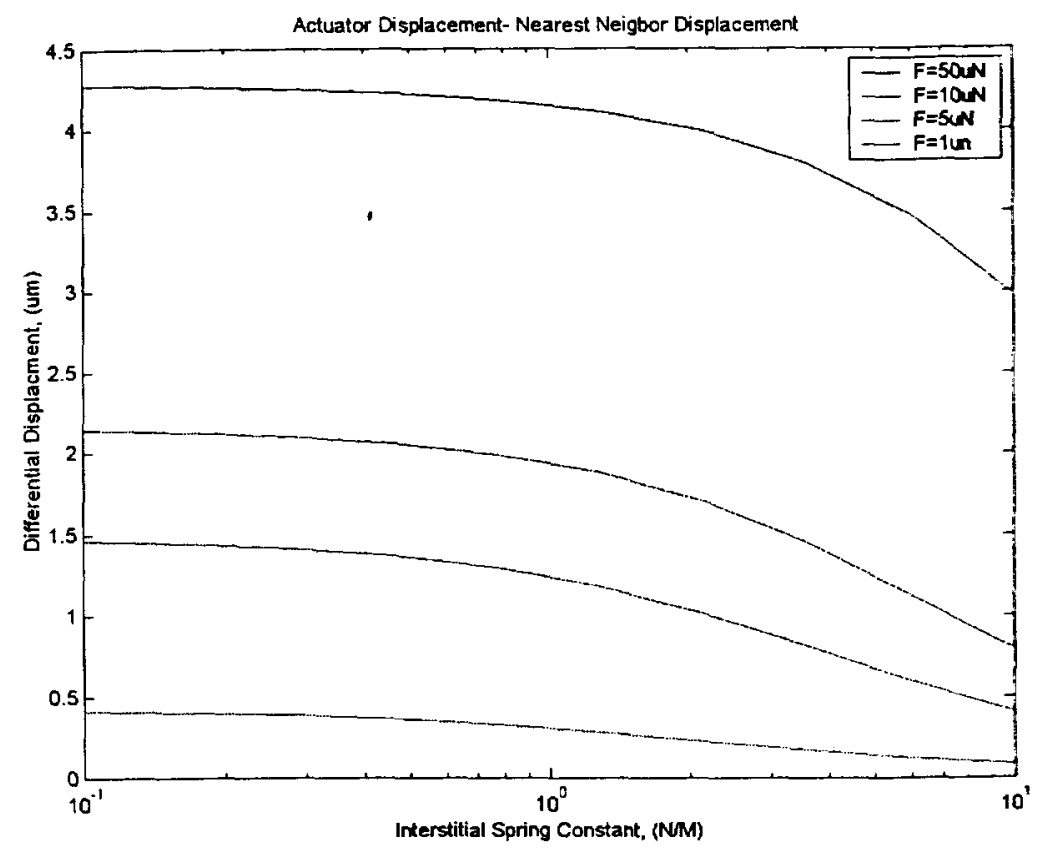

Figure 13 Spring System Results

\section{Conclusions}

The models suggest that that the greatest differential displacements possible from silicon membrane mirrors with conventional parallel plate electrostatic actuators will never be on the order of 30 microns. The work on alternate materials showed that less stiff materials such as polyimide and mylar may come much closer to those deflections. The models suggest that a 3 layer architecture mirror is capable of around 2 microns of actuator to actuator deflection with around $15 \%$ influence on its neighbors decreasing to around 1.2 microns with around $9 \%$ influence.

[1] Timoshenko, S., "Theory of Plates and Shells", McGraw Hill, New York, 1940

[2] Davis, W., "Mechanical Analysis and Design of Vibratory Micromachined Gyroscopes", Ph.D. Dissertation, University of California Berkeley, Berkeley California, 2001. 